\title{
Repercussions of language difficulties in people with amyotrophic lateral sclerosis and the impact on their lives and on their caregivers
}

\author{
Lavoisier Leite Neto ${ }^{1}$ \\ https://orcid.org/0000-0002-7796-5973 \\ Thais Novais ${ }^{2}$ \\ https://orcid.org/0000-0002-5387-0080 \\ Marcondes França Júnior ${ }^{3}$ \\ https://orcid.org/0000-0003-0898-2419 \\ Regina Chun ${ }^{1}$ \\ https://orcid.org/0000-0002-5305-7081
}

Universidade Estadual de Campinas UNICAMP, Faculdade de Ciências Médicas, Departamento de Desenvolvimento Humano e Reabilitação, Programa Saúde, Interdisciplinaridade e Reabilitação, Campinas, São Paulo, Brasil.

Universidade Estadual de Campinas UNICAMP, Faculdade de Ciências Médicas, Curso de Fonoaudiologia, Campinas, São Paulo, Brasil.

${ }^{3}$ Universidade Estadual de Campinas UNICAMP, Faculdade de Ciências Médicas, Departamento de Neurologia, Campinas, São Paulo, Brasil.

Research support source: Coordenação de Aperfeicoamento de Pessoal de Nível Superior (CAPES).

Conflict of interests: Nonexistent

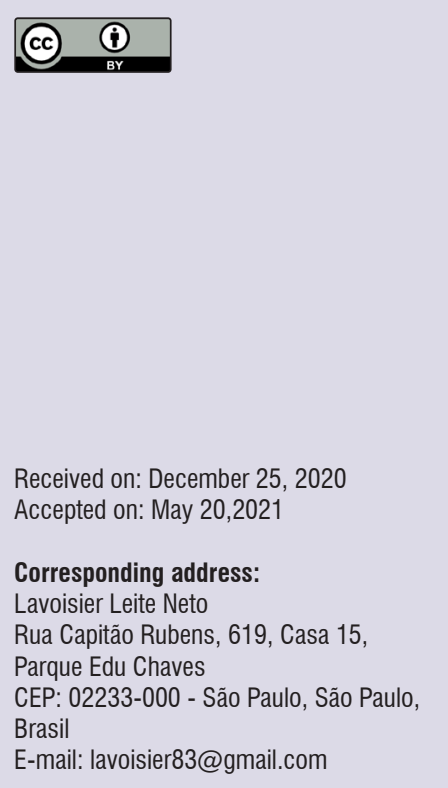

\section{ABSTRACT}

Purpose: to analyze the repercussions of language difficulties in people presented with Amyotrophic Lateral Sclerosis and in their caregivers, and the impact on their lives.

Methods: a cross-sectional study and qualitative approach, structured according to the COREQ. Semi-structured interview was conducted with 30 participants, family members and/or caregivers of people with the disease, most of them diagnosed for less than 5 years, and then transcribed and analyzed under repetition and relevance criteria.

Results: most participants were women, spouses, between 50 and 70 years of age, in average being a caregiver for less than 3 years. Most interviewees reported the absence of communication difficulties with the disease, little use of Augmentative and Alternative Communication, restricted social interaction, and the perception of signs of discouragement and sadness in the person under their care. Regarding themselves, they mentioned anguish related to the prognosis, emotional overload, and intense change of routine in their lives.

Conclusion: language difficulties were not frequently reported, despite the observation of restricted and social interactions. These findings showed the negative impacts on the quality of life of individuals and that of their family members and caregivers, which are experienced as anguish.

Keywords: Amyotrophic Lateral Sclerosis; Health Vulnerability; Family; Communication Barriers; Caregivers 


\section{INTRODUCTION}

Amyotrophic Lateral Sclerosis (ALS) is a neurodegenerative disease that affects motor neurons in bulbar, cervical, thoracic and lumbar levels, and evolves to weakness of upper and lower limbs, dysarthria, dysphagia, cognitive and behavioral alterations, culminating with the loss of functional capacity by the individual ${ }^{1}$. Currently, a cure to this disease is unknown, and patients need multidisciplinary and cross-disciplinary health care throughout the disease progression, in order to delay the onset of alterations and improve their quality of life ${ }^{2-4}$.

Under such circumstances, speech alterations and the possible absence of speech, in advanced stages of the disease, turn it difficult to the individual to interact with family members, medical team and close friends, limiting their autonomy and decision making, also concerning their own treatment, which results in fear, anxiety, frustration and sadness ${ }^{5}$. The impact of this condition is significantly experienced within the family, and often with little guidance and lack of specialized clinical and therapeutic monitoring.

The use of Augmentative and/or Alternative Communication (AAC) Systems is a feasible and effective strategy in such conditions of speech impairment, to minimize its impact and facilitate the interaction with the interlocutor, so that communication does not depend on the presence of a mediator/interpreter $^{5}$. However, it isn't rare to find difficulties and barriers to incorporate communication systems to the routine of the ALS individual, which contributes to the little adherence to the AAC, both by the patient and the caregiver $^{6}$, as also addressed in other studies regarding other pathologies ${ }^{7}$.

Such progressive speech alterations and difficulty to adapt to resources interfere with the communicative interaction, which can be understood as the individual involvement in communication-related activities in each social circumstance where they occur ${ }^{8}$, worsening their quality of life and moving them increasingly away from other people ${ }^{5}$. Furthermore, this creates a condition of communicative vulnerability in the hospital setting, as discussed in another work, also resulting from other neurological conditions ${ }^{9}$.

The fast and progressive nature of the disease, to which other particularly debilitating effects are added, such as speech loss, transition to assisted ventilation and palliative care, in the last months of life, frequently turn ALS individuals dependent on third parties, needing support for most of the life activities ${ }^{10}$.
The huge demand of work, combined with treatment uncertainties, can generate feelings of overload and frustration in the family member and/or caregiver, which directly affects the assistance they provide ${ }^{11,12}$.

Since the initial diagnosis, family has a key role, generally being the principal responsible for providing support to the treatment and in the process of the individual's acceptance of the reality. Most of the times, a major adaptation of the daily routine to the needs of the ALS individual under care is necessary, with the family member having to leave work, also abdicating to take part in leisure and social activities ${ }^{13}$.

When someone lives with/take care of someone with a chronical neurological disease, such as ALS, this person must deal with the unexpected, while having to manage one's own life and family (spouse and children), also being responsible for the emotional, physical, psychological, and financial support of the individual being taken care of. Thus, family members feel alone and place the needs of the individual being taken care of as a priority, neglecting their own desires and personal issues ${ }^{14}$.

In this scenario, it is important that professionals involved in the assistance to ALS individuals be alert to the demands from family members and/or caregivers, who not always can provide the necessary everyday support, and often feel exhausted because of the daily routine ${ }^{10,13,14}$. Overloaded and not rarely under major stress, such situation can affect the quality of caregiving they provide in the hospital setting and outside $\mathrm{it}^{15}$.

Several research ${ }^{11,13,15}$ have been developed with the aim of understanding the repercussions for caregivers/ family members in the caregiving process, as well as their perspectives regarding the situations they are exposed to, also considering the increasing daily difficulties presented by the individual with worsening health conditions, to provide the best service to this population group.

In this regard, this study stands out for addressing the impact of language alterations and its developments on the lives of ALS people and their family members and/or caregivers, and therefore, this is the main differential in relation to other research developed in this line, to provide more intensification of the topic and quality to the assistance provided to such family members and/or caregivers, and consequently, to the individual they take care of.

Hance, the purpose of this work is to analyze the repercussions of language difficulties in people 
presented with Amyotrophic Lateral Sclerosis and their caregivers, and the impact on their lives.

\section{METHODS}

This is a cross-sectional and qualitative approach research, approved by the Ethics and Research Committee (CEP) of the State University of Campinas, School of Medical Sciences, Brazil, under no. 1.942.954.

The study was structured according to the Consolidated Criteria for Reporting Qualitative Research (COREQ), comprised by 32 items, divided into three domains: "research team and reflexivity" (8 items), "study design" (15 items), and "analysis and findings" (9 items) $)^{16}$.

During the study development process, all the steps and procedures were discussed by the responsible researcher, adviser, and co-adviser, from the elaboration of the interview script (ANNEX 1), using the analysis and discussion of results, and counting on the participation of a Speech and Language Therapy student, who supported the task of interviews transcription and the partial data analysis.

\section{Constitution of the Sample}

The sample was obtained through a convenience sampling with 30 participants, family members and/ or caregivers of individuals with ALS, seen in the Outpatient Clinic of Neuromuscular Diseases at a School Hospital of a university in the interior of São Paulo State. There was no contact between the interviewees and the data collection researcher before the beginning of interviews, which took place in person in previously scheduled times, according to the routine defined by the facility, with no need of participants to come in other days and times. The inclusion criteria comprised the following: to be 18 years old or more, of both sexes, and be a family member/caregiver of an individual with ALS seen by the health care professionals in this Outpatient Clinic. The exclusion criteria were the following: family members or people accompanying the ALS individuals who were unaware of the disease track records and of the communication conditions of the person under their care during the data collection period.

\section{Collection Procedures}

In the first contact with the participants, the research and data collection responsible researcher were introduced, including the researcher educational background, experience with the research, and motivation to perform the study, in addition to explaining the purposes and procedures of the research, and the Free, Prior and Informed Consent was read. Only after the consent to the terms and signature of the FPIC, data collection started.

To obtain data, participants were taken by the researcher to a silent room, with the minimum external noise, where the interview was individually done, through a semi-structured script.

The interview script (ANNEX 1) was elaborated by one of the researchers and reviewed by one of the advisers, with the aim of checking the conditions and communication media of the individual with ALS, the impact of speech and language alterations in the family, social and professional lives, communication in different situations, relationship with the family members and close friends, prior experience in using the AAC, participation or not of a facilitator, environmental interferences, alert conditions, motor, perceptive and sensorial conditions, signs of fatigue, as well as the impacts of alterations experienced during the ALS on the lives of family members and/or caregivers.

During the interview, only the responsible researcher and the interviewee were present, without the ALS individual under the interviewee's care, to prevent interferences or embarrassments to any of the involved parties, either a family member or the caregiver or the individual with ALS. The interviews lasted in average forty minutes each, and were recorded in video, upon the participant's authorization, for subsequent transcription and analysis. The digital camera Canon Powershot SX530 HS and mini tripod were used to a better stabilization and adjustment of images. Participants remained seated.

A pilot study was conducted with two volunteers who met the inclusion criteria, to analyze the elaborated script, allowing it to be changed and perfected, in addition to check how to apply it.

\section{Data Analysis Manner}

Data were transcribed and analyzed by the main researcher, who counted on the support from a scientific initiation student during the transcription phase. After that, thematic axes and analysis categories were defined ${ }^{17}$, using repetition and relevance criteria $^{18}$, described as follows in Figures 1 and 2. 


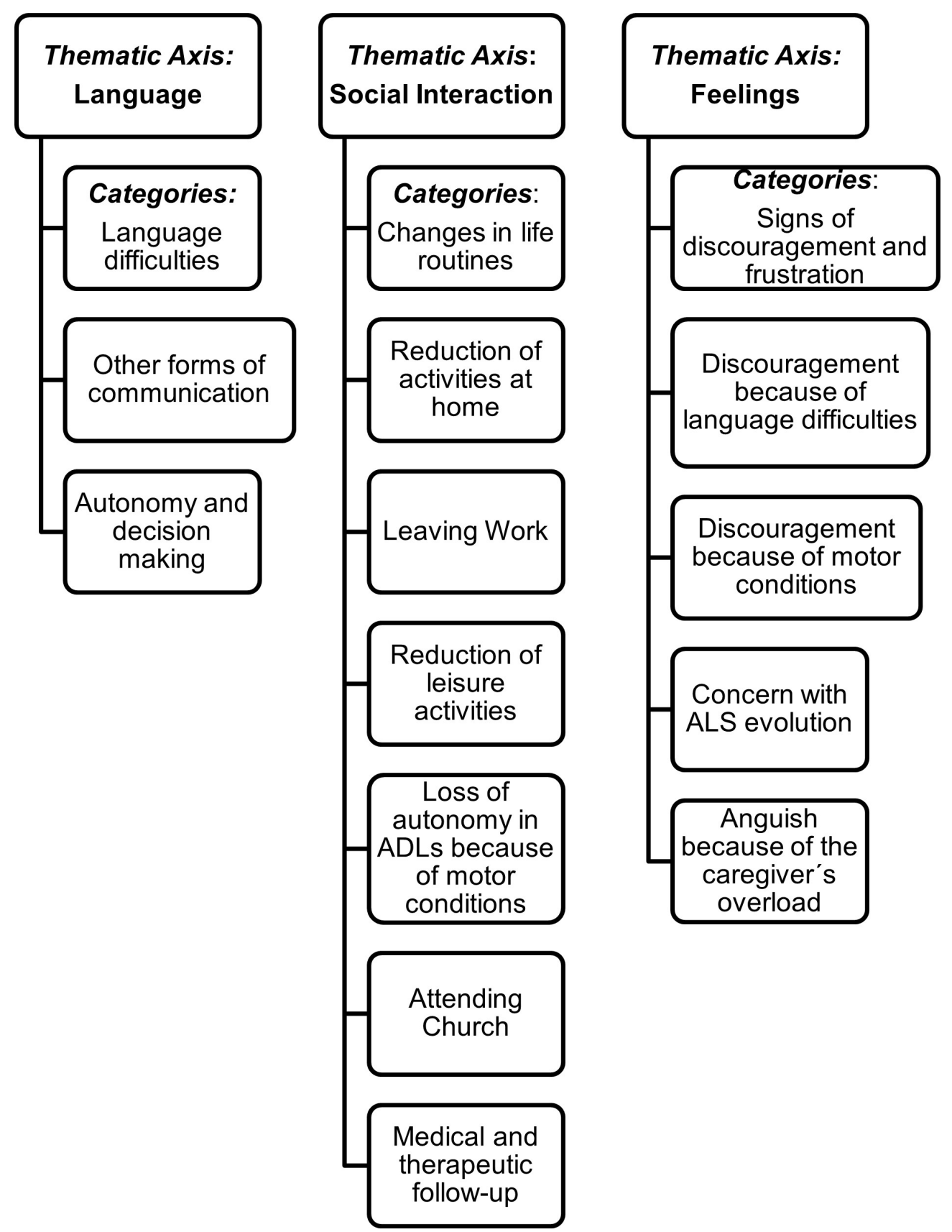

Caption: ADLs - Activities of Daily Life; ALS - Amyotrophic Lateral Sclerosis

Figure 1. Thematic axes and analysis categories of individuals under the care of the interviewees 


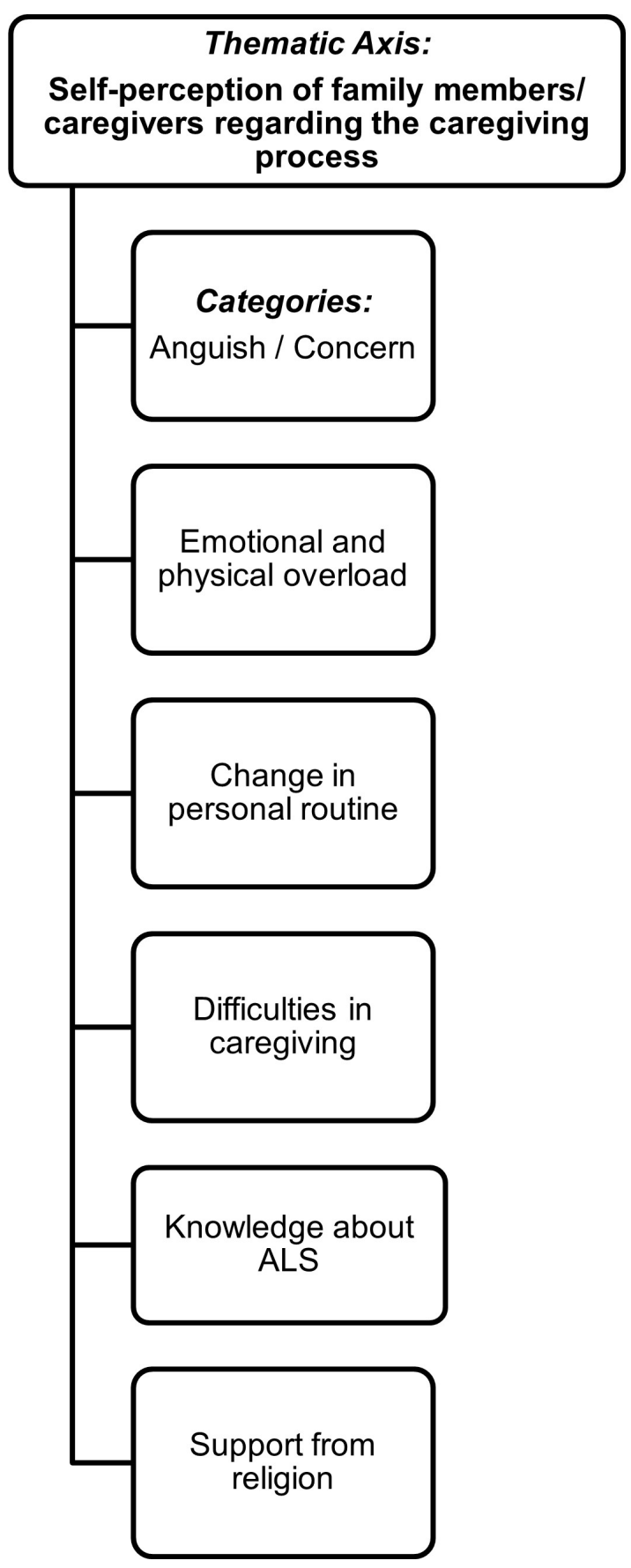

Caption: ALS - Amyotrophic Lateral Sclerosis

Figure 2. Thematic axes and analysis categories related to the family member and/or caregiver

Interview transcriptions were not given to the participants, because such procedure was not foreseen in the routine of the ALS individuals' outpatient clinic, and because the person accompanying the ALS individual in the return to the clinic could vary.

\section{RESULTS}

\section{Sociodemographic and caregiving profile of the research participants}

Chart 1 shows the study participants' profile regarding sex, age, years of study, caregiving relation and caregiving time with the ALS individual under their responsibility. Those data were surveyed during the conduction of interviews, therefore we decided to present them as the results.

Table 1 shows the distribution of participant family members and/or caregivers per age range, sex, years of study, caregiving time and caregiving relation with the ALS individual.

Most of the interviewees are spouses or children of the ALS individuals, having taken care of them since the first symptoms. A small number are formal or informal caregivers, and of those, only one has a background in the field of Health Care (nursing technician), and the others are close friends or neighbors.

Language, social interaction, and impact on the life of the ALS individual

Table 2 as follows shows the results regarding the perception of family members and/or caregivers of the language of the ALS individual under their care.

Most interviewees said that the interaction facilitates the dialogue, and in the daily routine they manage to understand what the individual under their care says, as shown by parts of the interviews of participants S2 and S11:

"I have already got used. Sometimes, something, when he is more agitated, when he talks faster, he has difficulty to express himself, but usually I can understand everything." (Participant S2)

“(...) for instance, me and my children, we understand because we are all the time with him, but people of the family in general, they ask again what he said." (Participant S11)

Of the participants declaring to perceive difficulties in the language, all of them stressed that in relation to close friends and neighbors, this issue is even worse for the individual under their responsibility.

According to the reports, language difficulties appear more intensely in specific moments, such as in conversations over the phone, situations of stress, in addition to when the individual is not willing to communicate, or even when there is a variation in the mood and emotional state, as demonstrated by parts of the interviews of participants S3 and S12: 
Chart 1. Sociodemographic and caregiving profile of the research participants $(n=30)$

\begin{tabular}{|c|c|c|c|c|c|}
\hline & Age & Sex & Years of study & Caregiving relation & $\begin{array}{c}\text { Caregiving time } \\
\text { (years) }\end{array}$ \\
\hline S1 & 35 & $\mathrm{M}$ & 11 & Son & 9 \\
\hline S2 & 60 & $\mathrm{~F}$ & 11 & Mother & 4 \\
\hline S3 & 29 & $\mathrm{~F}$ & 15 & Sister & 8 \\
\hline S4 & 42 & $\mathrm{~F}$ & 15 & Daughter & 4 \\
\hline S5 & 56 & $\mathrm{~F}$ & 4 & Sister-in-law & 5 \\
\hline S6 & 57 & $\mathrm{M}$ & 11 & Brother & 1 \\
\hline S7 & 45 & $F$ & 15 & Daughter-in-law & 2 \\
\hline S8 & 60 & $\mathrm{~F}$ & 11 & Wife & 1 \\
\hline S9 & 28 & $\mathrm{~F}$ & 15 & Daughter & 9 \\
\hline $\mathrm{S} 10$ & 51 & $\mathrm{~F}$ & 15 & Wife & 5 \\
\hline S11 & 54 & $\mathrm{~F}$ & 15 & Wife & 6 \\
\hline S12 & 51 & $\mathrm{~F}$ & 8 & Caregiver & 1 \\
\hline S13 & 65 & $\mathrm{M}$ & 4 & Brother-in-law & 2 \\
\hline S14 & 51 & $\mathrm{~F}$ & 15 & Wife & 1 \\
\hline S15 & 42 & $M$ & 11 & Husband & 4 \\
\hline S16 & 35 & $\mathrm{~F}$ & 11 & Wife & 8 \\
\hline S17 & 30 & M & 15 & Son & 2 \\
\hline S18 & 31 & M & 11 & Son & 1 \\
\hline S19 & 52 & $\mathrm{~F}$ & 2 & Caregiver & 2 \\
\hline S20 & 61 & $\mathrm{~F}$ & 6 & Wife & 1 \\
\hline S21 & 64 & $\mathrm{~F}$ & 11 & caregiver & 1 \\
\hline S22 & 32 & $\mathrm{M}$ & 15 & Son & 3 \\
\hline S23 & 43 & $\mathrm{~F}$ & 5 & Wife & 13 \\
\hline S24 & 60 & $\mathrm{M}$ & 10 & Brother & 3 \\
\hline S25 & 40 & $\mathrm{~F}$ & 15 & Caregiver & 1 \\
\hline S26 & 51 & $\mathrm{~F}$ & 11 & Wife & 2 \\
\hline S27 & 30 & $\mathrm{M}$ & 11 & Son & 1 \\
\hline S28 & 57 & $\mathrm{~F}$ & 11 & Mother & 1 \\
\hline S29 & 49 & $\mathrm{~F}$ & 11 & Wife & 1 \\
\hline S30 & 56 & $\mathrm{~F}$ & 11 & Wife & 1 \\
\hline
\end{tabular}

"For instance, he doesn't pick up the phone to call anybody, because he says there is always someone that will not understand him (...)" (Participant S3)

"Today, she was not in high spirits, and we notice that she stays silent, not communicating so much". (Participant S12)

Seven interviewees reported that the individuals taken care of used other ways of communication, when communicating through speech fails. The most frequently mentioned strategies included gestures, writing, and typing on the cellphone, as pointed out by participants S7, S8 and S18 as follows:
"There are some days when I manage to understand more, but when I have too much difficulty, I give her a sketch board and ask her to write to me". (Participant S7)

"It is difficult, and if we pay attention, we end up understanding. And when he sees that we are not understanding, he makes some gesture". (Participant S8)

"Sometimes when she is a little nervous, she can't speak, then she types". (Participant S18) 
Table 1. Distribution of participants per age group, sex, years of study, time from the disease diagnosis, caregiving time and caretaking relation with the individual with Amyotrophic Lateral Sclerosis $(n=30)$

\begin{tabular}{lc}
\hline Age group & Frequency $\mathbf{n}(\%)$ \\
\hline$<30$ years & $2(6.67)$ \\
30 to 49 years & $12(40.00)$ \\
50 to 70 years & $16(53.33)$ \\
Sex & \\
Women & $21(70.00)$ \\
Men & $9(30.00)$ \\
Years of study & \\
$<5$ years & $3(10.00)$ \\
5 to 11 years & $17(56.67)$ \\
$>11$ years & $10(33.33)$ \\
Years of caregiving & \\
$<3$ years & $17(56.67)$ \\
3 to 6 years & $8(26.67)$ \\
$>6$ years & $5(16.66)$ \\
Caregiving relation & \\
Family member & $26(86.67)$ \\
Caregiver & $4(13.33)$ \\
Time from ALS diagnosis & \\
$<5$ years & $20(66.66)$ \\
$\geq 5$ years & $10(33.34)$ \\
\hline
\end{tabular}

Table 2. Perception of family members and/or caregivers of the language of the individual under their care $(n=30)$

\begin{tabular}{lcc}
\hline \multirow{2}{*}{ Language } & Yes & No \\
\cline { 2 - 3 } & Frequency $\mathbf{n}(\%)$ & Frequency $\mathbf{n}(\%)$ \\
\hline Language difficulties & $11(36.66)$ & $19(63.34)$ \\
Other forms of communication & $7(23.33)$ & $23(76.67)$ \\
Autonomy/decision making & $5(16.66)$ & $25(83.34)$ \\
\hline
\end{tabular}

Another reported strategy, by a single participant, was the use of a bell so that the individual could call the attention of family members.

"One of the first things we got for her was this little bell. Because, for instance, if she is in another room, she can't scream or call us". (Participant S17)

One of the participants said he was against other ways of communication, such as writing, because he believed it could interfere with the possibility of speech.

"I think this is not ok, because if she does not have the possibility of trying to speak, I think it is not a good thing for her to write. Then, I think this restricts her, isn't it? (...) it is a disadvantage to use writing because it impedes her to speak, to stimulate speech". (Participant S19)
When asked whether the language difficulties interfered with the autonomy and decision making of the ALS individual, almost everybody said they do not perceive such aspect. However, the reports of those agreeing on the interference show to be significant and brought about topics such as isolation and shame of the limitations present in the ALS. Part of S11 participant interview is shown as follows.

"He is avoiding talking to other people, he seems to be a little scared to talk, because I think other people are noticing this, he starts to question and isolates himself". (Participant S11)

Such topics refer us to social interaction and routine related changes, inside and outside home, as shown in Table 3. 
Table 3. Perception of family members and/or caregivers of changes in the social interaction of the individual under their care $(n=30)$

\begin{tabular}{lcc}
\hline \multirow{2}{*}{ Social interaction } & Yes & No \\
\cline { 2 - 3 } & Frequency $\mathbf{n}(\%)$ & Frequency $\mathbf{n}(\%)$ \\
\hline Changes in life routine & $24(80.00)$ & $6(20.00)$ \\
Reduction of activities at home & $24(80.00)$ & $6(20.00)$ \\
Leaving work & $27(90.00)$ & $3(10.00)$ \\
Reduction of leisure activities & $24(80.00)$ & $6(20.00)$ \\
Loss of autonomy in ADLs because of motor conditions & $16(53.33)$ & $14(46.67)$ \\
Attending church & $3(10.00)$ & $27(90.00)$ \\
Medical and therapeutic follow-up & $29(96.67)$ & $1(3.33)$ \\
\hline
\end{tabular}

Caption: ADL - Activity of Daily Life

Most of the participants was emphatic about the changes in the social interaction and life routine of the individual under their care, experienced by some in a sudden way, and by others, gradually according to the ALS progression. The following was reported: reduction of activities done at home, leave from work, and reduction in the participation of activities the individual liked to do before, such as leisure and going to the church. The interviewees related such changes to the emotional and motor conditions, and represent an impact on the quality of life of the individual under care, as shown by parts of the interviews of $\mathrm{S} 5, \mathrm{~S} 7$ and S11:

"Before he used to go out, to have a coffee in the bakery shop. Now, he no longer goes there because he has a hard time walking. Then I think he is becoming scared to walk too much, to make too much effort and get tired, that is it". (Participant S5)

"He liked to go to the Bingo on Sunday, sometimes to the church, he used to participate a lot in church activities, to pray, but now he no longer does that". (Participant S7)
"He wakes up kind of dragging himself. He has already changed his routine because he used to go out more, and today he no longer does that. For instance, depending on the place, he thinks it over before going". (Participant S11)

Some interviewees mentioned the loss of autonomy to perform routine activities, because of motor difficulties, with the individuals doing that more slowly and awkwardly, such as in the case of S9.

"She has difficulty to shower, I sit her on the chair, and she showers herself, sometimes I help (...) she needs help to go to the toilet, to rise from the toilet seat, to dress herself, the lower part makes it difficult for her to balance herself". (Participant S9)

The main activity performed at home by ALS individuals, according to the reports of family members and/or caregivers, was watching TV, most of the time, going to the church sporadically, and going to medical/ therapeutic appointments.

The following Table 4 shows the results regarding family members and/or caregivers' perceptions of the feelings of individuals taken care of regarding the ALS.

Table 4. Perception of family members and/or caregivers of the feelings of individuals taken care of, regarding the Amyotrophic Lateral Sclerosis $(n=30)$

\begin{tabular}{lcc}
\hline \multirow{2}{*}{ Feelings } & Yes & No \\
\cline { 2 - 3 } & Frequency $\mathbf{n}(\%)$ & Frequency $\mathbf{n}(\%)$ \\
\hline Signs of discouragement and frustration & $18(60.00)$ & $12(40.00)$ \\
Discouragement because of language difficulties & $1(3.33)$ & $29(96.67)$ \\
Discouragement because of motor conditions & $15(50.00)$ & $15(50.00)$ \\
Concerns with ALS evolution & $6(20.00)$ & $24(80.00)$ \\
Anguish because of the burden on the caregiver & $3(10.00)$ & $27(90.00)$ \\
\hline
\end{tabular}

Caption: ALS - Amyotrophic Lateral Sclerosis 
The interviewees said to notice signs of discouragement and sadness in the individual under their responsibility, expressed by constant crying, stress, frustration and concern for the evolution of the disease, as shown in parts of the interviews with participants S7 and S14.

"I think she is depressed because she no longer wants to leave home. Even when we are there, sometimes I say: 'come to the living room, come watching a movie we will play', but she doesn't want, she stays there laying on her bed, or sit on an armchair". (Participant S7)

"Then I notice that he is sometimes sad, he is overwhelmed by this disease, he says he is useless (...). He said he is more emotional, feels more like crying, and that is true". (Participant S14)

Interviewees' reports show that the distress experienced because of the disease progress is also related to the unsatisfaction regarding the trouble caused to the family member and/or caregiver, and only one participant related the individual sadness to the language difficulties. Others referred to the motor conditions and loss of functional capacity caused by the ALS. As observed in the reports of S8 and S17:

"There are somedays when he is upset, sad, because although I try to be strong, I can't, then somedays I also cry. Sunday, for instance, he looked me in the face, and I cried all the time, and obviously he starts to cry for seeing me like that". (Participant S8)

"I think she has frustration, for having this hard time to communicate (....), sometimes she even complains a little, even if inside her head she thinks "I am a burden", but then we tell her that if it were us, she would do the same". (Participant S17)

In some interviews, important reports regarding prejudices from other people related to the disease were reported, since some people avoided contact with the ALS individual. Furthermore, they reported that ALS individuals feel ashamed and said they do not feel comfortable when asked about their limitations.

This was the main justification given by family members and/or caregivers for the perceived isolation, expressed by the reduced social life and leisure activities, on the part of the individual under their care, even when invited to go out, they decide to stay home.

Self-perception of family members and/or caregivers regarding the caregiving process

Table 5 shows the results regarding the selfperception of family members and/or caregivers, participants of the research, based on their experience with the caregiving process.

Table 5. Self-perception of family members and/or caregivers of the aspects experienced in the caregiving process $(n=30)$

\begin{tabular}{lcc}
\hline \multirow{2}{*}{ Aspects experienced } & Yes & No \\
\cline { 2 - 3 } & Frequency $\mathbf{n}$ (\%) & Frequency $\mathbf{n}$ (\%) \\
\hline Anguish/concern & $28(93.33)$ & $2(6.67)$ \\
Emotional and physical overload & $12(40.00)$ & $18(60.00)$ \\
Change of personal routine & $20(66.66)$ & $10(33.34)$ \\
Difficulties in caregiving & $10(33.33)$ & $20(66.67)$ \\
Enough knowledge of ALS & $12(40.00)$ & $18(60.00)$ \\
Support from religion & $3(10.00)$ & $27(90.00)$ \\
\hline
\end{tabular}

Caption: ALS - Amyotrophic Lateral Sclerosis

Most of the participants showed to be distressed and/or concerned with the evolution of the disease, and the gradual loss of motor capacity by the individual under their care. A mother was outraged by her son's situation. Among the changes in life routine, she mainly mentioned her leaving the work to become more focused on the day-to-day of the individual taken care of. In addition to this responsibility, allied to the physical and emotional overload, caregiving generates major suffering to the interviewees, as shown by the interviews of S2 and S8: 
"I feel revolt [cry]. Sorry son, but I am revolted because my son did not deserve that, I have a very big revolt inside me, but lots of faith, you know? I do not accept that for him, I never said that, but I do not accept, and for me he does not have this, I do not accept". (Participant S2)

"I have been living as a prisoner of a disease, every day I prepare myself for the worse, I feel extremely as an adrift boat (...) I feel like a beast of burden, a lifeless person who is living for another person, that is it".. (Participant S8)

When asked about specific difficulties in the caregiving process, a small number of participants reported to experience them specially in relation to the physical and emotional limitations of the individual under their care, as observed in the interviews of S7 and S20:

"My biggest difficulty is the emotional aspect, because my mother-in-law, she was always like...., she was less emotional, and know she cries for anything. I have a hard time because I don't want to be too invasive, you know?". (Participant S7)

"My difficulty to take care of him is that he likes to take shower, and not always there is someone available to help him, and I have to bath him in the living room. And the difficulty to move him around (...)" (Participant S20)

The support from religion was more clearly mentioned by three participants, evidencing that they get support from faith to face the demands from the family member with ALS of and the emotional overload. At some point, they still wait for a cure through a miracle, as shown by the interviews of $\mathrm{S} 4$ and $\mathrm{S} 16$ :

"I trust God a lot, I am very evangelic, and I know that what he has to go through, we need to support" In whatever necessary". (Participant S4)

"We believe in some kind of miracle in his life, that he will leave this chair, I think everything returns". (Participant S16)

Most of the interviewees said to believe they have enough knowledge about the disease, and that the main sources of information are the physicians, health care team and the Internet. Few participants had a background in health care or mentioned to have already taken care of ALS individuals or with difficulties alike.
"I have knowledge because of the experiences I had, my father-in-law, my mother-in-law, my mother, my grandmother, and in the health post. I read a lot! I research a lot! Doctor google provides me with lots of knowledge, of many things". (Participant S2)

"I have knowledge because I have attended some years of Physical Therapy school". I have also seen an ALS patient that time". (Participant S9)

Current research limitations on strategies to retard the progression of the disease, possibilities of cure, better resources and equipment helping the treatment, were other issues present in the interview of the family member and/or caregiver, and which intensified their feeling of helplessness.

\section{DISCUSSION}

Findings evidence that how family members and/or caregivers perceive and live with ALS individuals has a significant impact on the lives of such individuals and on their own lives, and consequently on the caregiving relation. Interviewees bring out reports of sadness, frustration, discouragement, stress, and anxiety, of both parties, related to the progression of the disease, and particularly to the motor limitations.

In addition, they manly refer to the physical and emotional overload, results similar to other studies results, which show that the more the disease progresses the bigger the dependency becomes ${ }^{15}$, when there is loss of mobility, communication difficulties and respiratory failure, which causes a series of interferences with the routine, health and wellbeing of ALS individuals ${ }^{19,20}$.

In this research, the prevalence of 45 years old or more women, wives, and who takes care since the first symptoms of the ALS individual, was bigger, which, according to another study ${ }^{19}$, increases the risk of morbidity, since this relates to the lack of social support, more hours taking care of the ALS individual, in addition to disregarding their own health, reaffirming the importance of specialized professionals' support to this group of family members and caregivers.

In ALS, speech impairment quickly evolves, limiting the social relation and causing isolation, and this vulnerability experienced in the communication process makes it difficult to express desires, aspirations, and needs, causing frustration, and largely impacting the routine ${ }^{5}$ and life, both of individuals taken care of and 
of interviewed family members and caregivers, as evidenced by the results found.

Despite this being a frequent reality of ALS individuals, the findings of this study evidence that the interviewees reported having little difficulties of language with the individual taken care of, indicating they understand most of their demands in the daily routine. This is justified for the fact that they know the routine and most urgent needs of the ALS individuals, which facilitates dialogue and minimizes the effects of the existing speech and language impair.

In the perception of nearly all family members and/ or caregivers, such difficulties, even when existent, have little interfered with the interaction and communication with the ALS individual. However, they report the impaired communication with other interlocutors, such as neighbors and friends.

Likewise, the study participants believe such language difficulties little interfere with the autonomy and decision making of the ALS individual under their responsibility. However, we point out that the interviewees caused to the researchers, during the conduction of interviews, the impression of not being sure of the actual meaning of "autonomy" and "independency" in decision making. In our opinion, findings seem contradictory to a certain degree, since participants reported that the choice was done because of the interaction and/or convenience, and because they understood the needs, and not because that was a choice of the ALS individual him/herself.

Although language difficulties were reported by some participants, the use of AAC as a dialogical interaction facilitating strategy was little mentioned. Furthermore, some of them said they do not know such systems, and others pointed out that their utilization could disturb speech improvement. However, it was noticed the use of other forms of communication, such as cellphones, writing and gestures that, by definition, are regarded as augmentative and/or alternative communication, although people in general do not know that.

Differently from the belief that AAC can inhibit speech, the scientific literature of the field says that using it can benefit language and the interaction of people with complex communication needs, with a positive impact on the quality of life, mood, and mental health of ALS individuals and their caregivers ${ }^{2,5}$, since it facilitates autonomy, social interaction, and supports decision making processes.
Despite the report of use of other strategies to facilitate communication and the acknowledgment of their importance when speech is unintelligible, participants also pointed out they do not attain more progress due to the existing motor difficulties. The interviewees point out that such limitations do not facilitate the access to the $A A C$, in addition to make them fear fatigue in the short run.

The lack of professional guidance is one of the major barriers for the use of the AAC, which takes place in a discontinuous fashion, converging to the findings of other studies ${ }^{6,7}$.

Despite the difficulty to communicate with family members and caregivers was not frequently reported, this difficulty with other people, such as friends and neighbors, was a different reality reported. Such results reiterate other studies showing that speech difficulties, with the need to repeat phrases, for instance, end up causing frustration, isolation, and reduction of communication situations ${ }^{4}$.

According to the interviewees, the more the individual condition worsened, the fewer were the activities performed, and they reported that the individuals taken care of spent most of the time watching TV. When asked about the impact of that condition on the life of the ASL individual, they said they feel that such situation made them sad, discouraged and increasingly silent. Even depression being one of the symptoms associated to ALS, it doesn't appear much in the literature $^{21}$, differently from the perception of this research participants who pointed out that they notice more discouragement, sadness, and social isolation of the ALS individuals in the course of the disease, as shown by the findings of this study.

Insofar ALS progresses, the suffering of family members and/or caregivers also increases. The tension in performing this role, due to the several demands generated by taking care of the individual, both physical and emotional, as well as the everyday responsibility for managing the health and administrative needs, ends up also causing harm to the quality of life, as addressed in other studies ${ }^{15}$, which corroborates the results of this research.

The findings show that this process is experienced with lots of anguish and suffering, similarly to research that associates the decline of quality of life of those managing their physical demands and the behavioral changes present in $\mathrm{ALS}^{19}$. Also in that regard, such authors observe that modifications in the couple's 
routine, loss of intimacy and exchange of caregiving roles, increasingly intensify this impact.

Furthermore, other authors ${ }^{14}$ point out that one of the more common consequences, in that situation, is the feeling of imbalance in the relationship with the family member receiving care. Researchers say there could be a detachment in this relation, either between life partners, or between an adult and the elderly parent, because the caregiver is more focused on the ALS individual and on managing the resources, and this becomes more intense when the individual is cognitively and behaviorally impaired.

Results show the impact on the life routine of the family member and/or caregiver, after the ALS diagnosis, which implies the attention focused on the individual under care. The participants' discourses are significant and express unsatisfaction, physical and emotional overload, solitude, signs of depression, anxiety, and concern for one's own health, as also shown in other studies ${ }^{11}$.

Findings evidence spirituality and religious beliefs as sources of support, and ways to deal with the distress resulting from the reality with the ALS, as described by some authors ${ }^{19}$, who consider the existence of a correlation between spirituality and stress. They also suggest that a spiritual counsel could be part of the team of assistance to the ALS individual.

In this research, most of the family members and/or caregivers reported not having difficulties in taking care of the individual under their responsibility. Furthermore, they said they have enough knowledge about the ALS. This finding differs from other studies that point out the lack of knowledge about the disease and negative experiences in the diagnosis and treatment, especially related to the lack of empathy from the medical team, as an aggravating factor of the quality of life, both the ALS individual and of his/her family member and/or caregiver ${ }^{11}$.

\section{CONCLUSION}

According to the findings of this study, it is observed that most participants are family members who perform the role of caregivers of ALS individuals, since the onset of the first symptoms. Most of them did not mention language difficulties in the daily routine with the person taken care of, indicating this is easier because of their constant interaction, even when there is some speech alteration. Furthermore, they were not perceived as limiting the autonomy and decision making by ALS individuals, when compared to physical and emotional limitations. The use of their own ways of communication was reported by few participants, thus, evidencing the lack of knowledge about the available resources and their benefits.

The results show a reduced social interaction by ALS individuals, difficulties to perform activities inside the residence, leave from work, and reduction of leisure activities, thus, revealing signs of isolation.

As for the impact of the disease and its limitations on the lives of family members and/or caregivers, they said that during the disease progression, there is a negative repercussion on their own perception and feelings, disturbing their quality of life.

The study points out signs of anguish, anxiety and concern for the prognosis and evolution of ALS individuals' limitations. In this regard, there were references to the physical and emotional overload, because they perceive themselves as responsible for managing the health and administrative needs of individuals under their care, making their routine focused on ALS individuals.

Therefore, it is important to pay close attention to the needs of caregivers, in addition to those of ALS individuals, creating a support network to follow up the damages caused by the ALS, in this caregiving relation.

\section{REFERENCES}

1. Hardiman O, Al-Chalabi A, Chio A, Corr EM, Logroscino G, Robberecht $W$ et al. Amyotrophic lateral sclerosis. Nat Rev Dis Primers. 2017;3:17071. DOI: 10.1038/nrdp.2017.71.

2. Körner S, Siniawski M, Kollewe K, Rath KJ, Krampfl K, Zapf A et al. Speech therapy and communication device: impact on quality of life and mood in patients with amyotrophic lateral sclerosis. Amyotroph Lateral Scler Frontotemporal Degener. 2013;14(1):20-5. DOI: 10.3109/17482968.2012.692382.

3. Felgoise SH, Zaccheo V, Duff J, Simmons Z. Verbal communication impacts quality of life in patients with amyotrophic lateral sclerosis. Amyotroph Lateral Scler Frontotemporal Degener. 2016;17(34):179-83. DOI: 10.3109/21678421.2015.1125499.

4. Leite Neto L, Constantini AC. Dysarthria and quality of life in patients with amyotrophic lateral sclerosis. Rev. CEFAC. 2017;19(5):664-73. DOI: http://dx.doi. org/10.1590/1982-021620171954017. 
5. Leite Neto L, Constantini AC, Chun RYS. Communication vulnerable in patients with amyotrophic lateral sclerosis: a systematic review. NeuroRehabilitation. 2017;40(4):561-8. DOI: 10.3233/NRE-171443.

6. Ray J. Real-life challenges in using augmentative and alternative communication by persons with amyotrophic lateral sclerosis. Commun. Disord. Q. 2015;36(3):187-92. DOI: https://doi. org/10.1177/1525740114545359.

7. Romano N, Chun RYS. A Augmentative and Alternative Communication use: family and professionals' perceptions of facilitators and barriers. CoDAS. 2018;30(4);e20170138. DOI: http://dx.doi.org/10.1590/2317-1782/20162017138.

8. Baylor C, Burns M, Eadie T, Britton D, Yorkston K. A qualitative study of interference with communicative participation across communication disorders in adults. Am J Speech Lang Pathol. 2011;20(4):269-87. DOI: 10.1044/1058-0360(2011/10-0084).

9. Chun RYS, Leite Neto L, Zaqueu VF, Maia ALW, Farias LP. Comunicação vulnerável em casos de alta complexidade: perspectiva de atuação e pesquisa fonoaudiológica em hospital-escola. In: da Silva RM, Bezerra IC, Brasil CCP, Moura ERF, editors. Estudos qualitativos: enfoques teóricos e técnicas de coleta de informações. Sobral: Edições UVA; 2018. p. 81-96.

10. Paskulin LM, Bierhals CCBK, dos Santos NO, Day CB, Machado DO, de Morais EP et al. Depressive symptoms of the elderly people and caregiver's burden in home care. Invest Educ Enferm. 2017;35(2):210-20. DOI: 10.17533/udea.iee. v35n2a10.

11. Aoun SM, Bentley B, Funk L, Toye C, Grande G, Stajduhar KJ. A 10-year literature review of family caregiving for motor neurone disease: moving from caregiver burden studies to palliative care interventions. Palliat Med. 2013;27(5):437-46. DOI: https://doi.org/10.1177/0269216312455729.

12. Watermeyer TJ, Brown RG, Sidle KC, Oliver DJ, Allen C, Karlsson J et al. Impact of disease, cognitive and behavioural factors on caregiver outcome in amyotrophic lateral sclerosis. Amyotroph Lateral Scler Frontotemporal Degener. 2015;16(56):316-23. DOI: 10.3109/21678421.2015.1051990.
13. Bierhals CC, dos Santos NO, Fengler FL, Raubustt KD, Forbes DA, Paskulin LM. Needs of family caregivers in home care for older adults. Rev Lat Am Enfermagem. 2017;25:e2870. DOI: http:// dx.doi.org/10.1590/1518-8345.1511.2870.

14. Sullivan $A B$, Miller $D$. Who is taking care of the caregiver? J Patient Exp. 2015;2(1):7-12. DOI: 10.1177/237437431500200103.

15. Creemers $\mathrm{H}$, de Moree $\mathrm{S}$, Veldink JH, Nollet $F$, van den Berg LH, Beelen A. Factors related to caregiver strain in ALS: a longitudinal study. J Neurol Neurosurg Psychiatry. 2016;87(7):775-81. DOI: 10.1136/jnnp-2015-311651.

16. Tong A, Sainsbury P, Craig J. Consolidated criteria for reporting qualitative research (COREQ): a 32-item checklist for interviews and focus groups. International Int J Health Care. 2007;19(6):349. DOI: https://doi.org/10.1093/intqhc/mzm042.

17. Laville C, Dionne J. A construção do saber: manual de metodologia da pesquisa em ciências humanas. 1a ed. Belo Horizonte, BH: Editora UFMG; 1999.

18. Turato ER. Tratado da metodologia da pesquisa clínico-qualitativa: construção teóricoepistemológica. 6aㅡ ed. Petrópolis, RJ: Vozes; 2003.

19. Pinho AC, Goncalves E. Are amyotrophic lateral sclerosis caregivers at higher risk for health problems? Acta Med Port. 2016;29(1):56-62. DOI: 10.20344/amp.6590.

20. Güell MR, Anton A, Rojas-Garcia R, Puy C, Pradas J. Comprehensive care of amyotrophic lateral sclerosis patients: a care model. Arch Bronconeumol. 2013;49(12):529-33. DOI: 10.1016/j. arbres.2013.01.013.

21. van der Hulst EJ, Bak TH, Abrahams S. Impaired affective and cognitive theory of mind and behavioural change in amyotrophic lateral sclerosis. J Neurol Neurosurg Psychiatry. 2015;86(11):1208-15. DOI: 10.1136/ jnnp-2014-309290. 


\section{ANNEX 1 - SCRIPT OF THE INTERVIEW WITH FAMILY MEMBERS/CAREGIVERS}

Family Member/Caregiver:

Date of Birth:

Education (years of study):

Profession:

Family relationship:

For how long she/he takes care of the person:

Time from ALS diagnosis:

Interview date:
Sex:

Educational background:

Caregiver ( ) Companion ( )

Interviewer:

1. How and when ALS difficulties were noticed? What symptoms/signs were noticed by the person or by the family?

2. What cares have been taken ever since?

3. What medical and therapeutic procedures are performed by the individual under care?

4. Since ALS diagnosis, how is the speech of the person under your care? Do you think it is difficult to understand what the individual says?

5. If the individual shows difficulties, how is their communication with you and the others - family, friends, and neighbors?

6. Do you think these difficulties interfere with the life of the individual under your care? How? Do you think they interfere with the process of autonomy, choice and decision making?

7. Does the person under your care use some other form of resource to communicate? If yes, what are the facilities and difficulties in using this communication resource?

8. After ALS diagnosis, how is the feeding of the person under your care? Does he/she have difficulties to swallow, chew, or with different food consistencies? Loss of appetite? Need of help?

9. Since ALS diagnosis, do you observe changes of attention and memory of the person under your care?

10. After ALS diagnosis, do you note signs of depression of the person under your care?

11. After ALS diagnosis, were there changes in the life routine of the person under your care inside and outside home?

12. What activities the person under you care usually performs at home? Does he/she perform activities of daily life alone or with help? Does he/she have reading habits?

13. What activities the person under your care performs outside home? Does he/she keep leisure habits and social life (church, movies, visits to family members and friends, and others)?

14. Talk a little about yourself, what were the changes in your life after the ALS diagnosis of the person under your care? How are you feeling?

15. Do you think you have enough knowledge about ALS to take care of the person under your responsibility? What difficulties do you feel when taking care of the person under your responsibility? Is there any other information you would like to have?

16. Would you like to make any comments?

REMARKS: 